\title{
Counter-immunoelectro-osmophoresis for the detection of infantile gastroenteritis virus (orbi-group) antigen and antibody
}

\author{
P. J. MIDDLETON, M. PETRIC, C. M. HEWITT, M. T. SZYMANSKI, AND \\ J. S. TAM
}

From the Department of Virology, The Hospital for Sick Children, Toronto, Canada

SYNOPSIS A moderately sensitive, rapid, and economical test scheme for the detection of infantile gastroenteritis virus (IGV) in stool or antibody in serum has been developed and evaluated. The test scheme with minor modifications was an adaptation of a counter-immunoelectro-osmophoresis system we once used for the detection of hepatitis B antigen. Large numbers of stool samples may be screened during half a working day for the presence of IGV using reference antiserum to IGV prepared in guinea-pigs. Serological studies of a diagnostic but not epidemiological nature may also be performed with equal facility by this same test scheme using highly purified IGV antigen derived from stool.

A specific virus variously called orbi, reo-like, rota, or duovirus has now been found throughout the world (Kapikian et al, 1975). This virus is a major cause of gastroenteritis in infants and young children during colder months in temperate climes (Middleton et al, 1974; Davidson et al, 1975). Until further morphological studies (Martin et al, 1975) and the results of characterization tests have been published we prefer to employ the term and label the agent by the more descriptive name infantile gastroenteritis virus (IGV).

Our interest in IGV arose in the course of providing a clinical virology service to a large paediatric hospital. We have found that one electron microscopist and one electron microscope could handle approximately 20 samples per day. Since our service demands often exceeded this capability in gastroenteritis stool samples alone, it became imperative that we explore alternative yet equally rapid diagnostic methods. During the first four months of 1975 our service identified 190 IGV infections by negative contrast staining electron microscopy using non-purified unconcentrated stool samples. Five more identifications were made following stool or rectal swab eluate ultracentrifugation. Two additional and fatal cases were identified by indirect immunofluorescence of small bowel mucosa in this same time span.

Complement fixation as a means of providing a rapid diagnosis based on antigen detection was Received for publication 13 August 1975 discarded after a pilot study had shown that crude stool suspensions were often anticomplementary. From experience gathered in work on serum hepatitis, the technique of counter-immunoelectro-osmophoresis (CIEOP) suggested several advantages. By adopting a CIEOP system the anticomplementary problem might be avoided, large numbers of stool samples could be screened during one working day, and the volume of reactants used in the test system would be considerably less than those employed even in a conventional microcomplement fixation test. Moreover, crude stool suspensions might well contain a quantity of subvirion antigen which could migrate towards the anode under the influence of an electric field and produce precipitation lines with reference antibody.

\section{Material and Methods}

\section{CLINICAL SPECIMENS}

Stool specimens were collected from patients admitted to the Hospital for Sick Children, Toronto. Blood samples were either obtained from our diagnostic laboratory or collected in the course of a family study of acute gastroenteritis.

Stool containing Nebraska calf diarrhoea virus (NCDV) was kindly supplied by Dr Jan Thorsen, Ontario Veterinary College, University of Guelph.

COUNTER-IMMUNOELECTRO-OSMOPHORESIS

The technique employed was similar to that pre- 
viously used in our laboratory for hepatitis B antigen testing and was based on the method of Wallis and Melnick (1971) with minor modifications. We used a barbital tank buffer adjusted to a $\mathrm{pH}$ of 8.8 with 1N sodium hydroxide. The buffer was sterilized by pressure filtration through a Millipore $0.45 \mu \mathrm{m}$ filter, dispensed into $500 \mathrm{ml}$ amounts, and stored at $4^{\circ} \mathrm{C}$ until required. One percent agarose (Seakem, Marine Colloids Inc, distributed by Bausch \& Lomb Ltd) was prepared in a solution of 1 part tank buffer to 2 parts distilled water with the addition of $0.5 \%$ sodium azide as a preservative. Thus, the ionic strength of the buffer in the agarose was one-third that of the tank buffer.

Electrophoresis was carried out using a Shandon Electrophoresis Apparatus model U77 (Shandon Scientific Co, London, England) with the agarose on microscope slides. Wells were cut with a Culliford (1964) cutter. The pattern of wells is shown in figure 1. Antigen was placed in cathodal wells and antibody in anodal wells. Stool specimens were first diluted $1: 2$ in barbital buffer of the same ionic strength as that used to make up the agarose. Double strips of $1 \times 5$ in $(2.5 \times 12.7 \mathrm{~cm})$ Whatman No. 1 filter paper were used as wicks. A constant potential of 150 volts was applied for times varying between 30 and 180 minutes. Directly after electrophoresis for detecting antigen, each slide was treated with varying concentrations of tannic acid (British Drug Houses or Baker Chemical $\mathrm{Co}$ ) in distilled water for times varying from 15 to 180 minutes and precipitin lines were read on a darkground viewer (Shandon Scientific Co) while the slides were still immersed in tannic acid (Hopkins and Das, 1972). After electrophoresis for the detection of antibody, the slides were washed overnight in $0.85 \% \mathrm{NaCl}$ and then stained in tannic acid. For reference purposes slides stained in tannic acid were then washed for 15 minutes in distilled water and air-dried at room temperature or at $37^{\circ} \mathrm{C}$. Next, they were treated with $3.5 \%$ acetic acid for 10 minutes followed by $1 \%$ amido black in $7 \%$ acetic acid for 10 minutes. Excess amido black was removed by a rapid rinse in distilled water. The slides were then air-dried and stored. When slides were stained by amido black only, they were first washed overnight in $0.85 \% \mathrm{NaCl}$. Next morning they were rinsed in distilled water for 15 minutes, air-dried, and then stained with amido black as described above.

\section{PREPARATION OF IGV ANTIGENS}

The IGV antigens used in this study were prepared by the method of Petric et al (1975). Briefly, the virus was eluted from soiled diapers of infants diagnosed positive for IGV by electron microscopy, then partially purified by differential ultracentrifugation

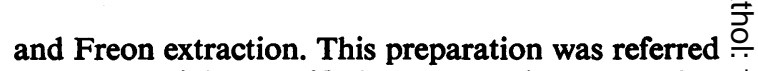
to as partially purified IGV antigen. Further $\overrightarrow{\overrightarrow{\mid}}$ purification of the IGV antigen was achieved either $\frac{\text { ? }}{0}$ by banding it twice on a $\mathrm{CsCl}$ gradient of starting density $1.36 \mathrm{~g} / \mathrm{ml}$ or by banding it once on a $\mathrm{CsCl} \frac{\partial}{\bar{\omega}}$. gradient and then sedimenting it through a sucrose $\frac{\vec{\sigma}}{\widetilde{\alpha}}$ gradient. This latter preparation was referred to as $\propto$ highly purified IGV antigen. Before use, virus so $\%$ purified was pelletted and resuspended in phosphate $\vec{\circ}$ buffered saline (PBS).

A 'soluble' IGV antigen was precipitated by $\vec{\omega}$ making the ultracentrifugal supernatant of the stool suspension up to $60 \%(\mathrm{w} / \mathrm{v})$ in ammonium sulphate? at $4^{\circ} \mathrm{C}$. The precipitate was dissolved in $1 \%$ of the original volume of PBS and dialysed against PBS $\omega$ overnight. After the insoluble components had been $\vec{\theta}$ removed by low-speed centrifugation the preparation $\vec{\circ}$ was stored at $-70^{\circ} \mathrm{C}$ until used.

PREPARATION OF IGV ANTISERA

Antibody to IGV was prepared in guinea-pigs as outlined in a previous publication (Middleton et al, $\vec{\imath}$ 1974). One lot of antiserum, here referred to as $\mathrm{PP} \mathscr{\theta}$ antiserum, was prepared by inoculating a guinea-pig. with partially purified IGV antigen, and a second lot, referred to as HP antiserum, was prepared by the inoculation of highly purified IGV antigen. $\bar{O}$ Before virus inoculation, $10 \mathrm{ml}$ of blood was collected from each animal by cardiac puncture. One $\stackrel{\unrhd}{\unrhd}$ month after inoculation the animals were bled dry $\overrightarrow{\overrightarrow{0}}$ by cardiac puncture.

\section{ELECTRON MICROSCOPY AND COMPLEMENT-} FIXATION TESTS

Electron microscopy (EM) was performed according? to the screening test described by Middleton et al 음 (1974). Complement-fixation tests (CF) were carried out in disposable microtrays, with overnight fixation 0 at $4^{\circ} \mathrm{C}$ using a microadaptation of the Bradstreet and Taylor (1962) method.

\section{Results}

\section{PARAMETERS OF THE CIEOP ASSAY}

\section{(a) Antigen}

When the same reference antiserum was used the? nature of the IGV antigen determined the numbero of precipitin lines produced between the cathodal $\bar{\varnothing}$ and anodal wells. Figure 1 shows the pattern of ${ }^{?}$ precipitin lines obtained with crude stool and highly purified and partially purified IGV antigens $\frac{\vec{\Phi}}{\mathbb{D}}$ versus the guinea-pig reference antiserum HP. Four $\stackrel{?}{?}$ lines, designated $1,2,3$, and 4 , invariably appeared $\stackrel{\Phi}{\complement}$ if partially purified IGV antigen was employedo (column $\mathbf{C}$ in fig 1). Crude stool antigen gave four 


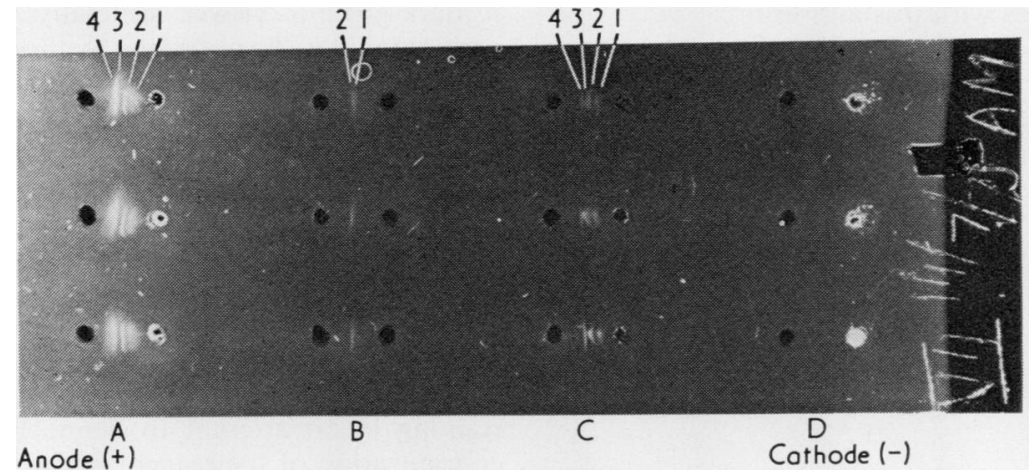

Fig 1 A CIEOP-reacted, agarose-coated microscopic slide $(3 \times 1$ in; $7.6 \times 2.5 \mathrm{~cm}$ ) showing triplicate results in the columns $A, B, C$, and $D$. Cathodal wells in columns $A$ and $D$ contain $a$ 1:2 dilution of an IGV positive crude stool; cathodal wells in column B contain highly purified IGV antigen; cathodal wells in column $C$ contain partially purified IGV antigen. Anodal wells in columns $A, B$, and $C$ contain postinoculation guinea-pig serum $H P$, the anodal wells in column $D$ contain preinoculation guinea-pig serum.

lines in $25 \%$ of samples tested (column $\mathrm{A}$ in fig 1) and in $75 \%$ of cases lines 1 and 2 only. The highly purified IGV antigen gave lines 1 and 2 only (column $B$ in fig 1). Lines 3 and 4 were obtained only with 'soluble' antigen.

Line 2 was cut out of the agarose (column C), homogenized in $1 \%$ ammonium acetate, and examined by negative contrast stain electron microscopy. The preparation showed aggregated IGV particles (fig 2). Lines 1, 3, and 4 did not contain recognizable viral structures by EM.

Control antigens derived from IGV negative stools did not produce precipitin lines with our reference antiserum. Furthermore, adenovirus positive stools

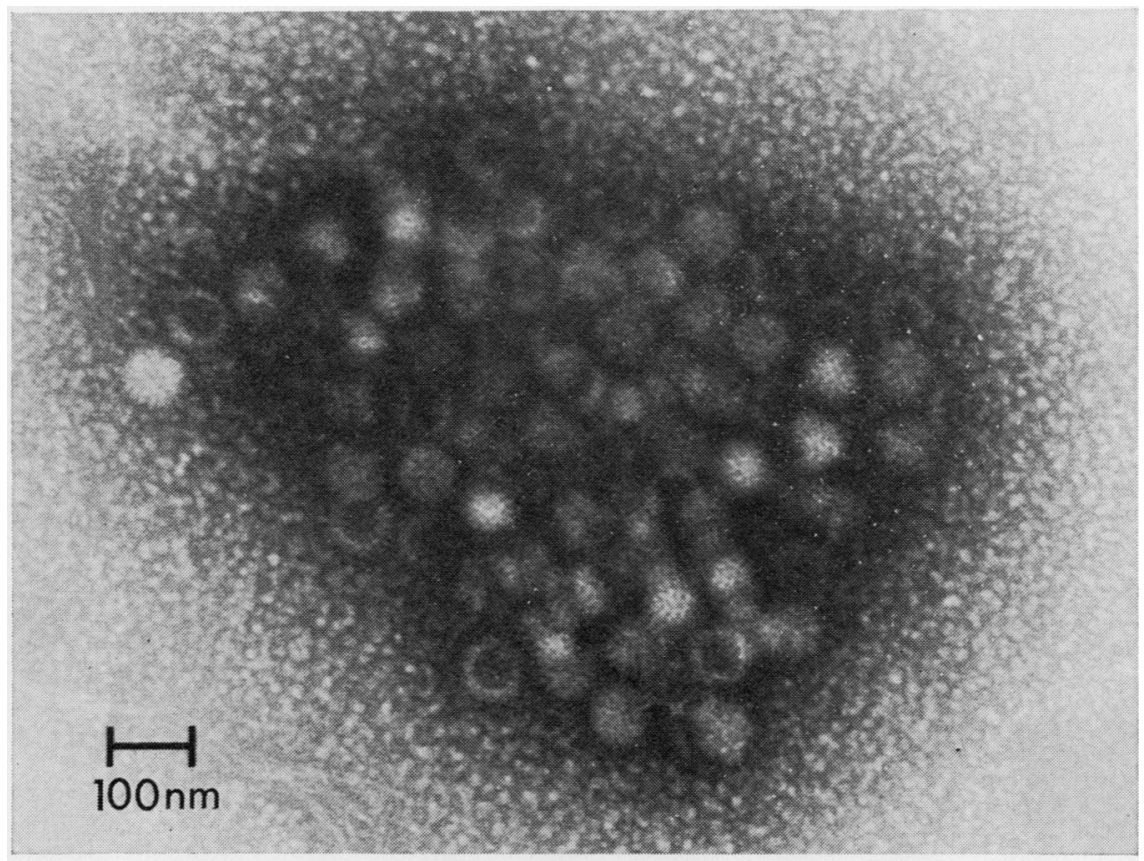

Fig 2 An aggregate of IGV particles obtained from line 2 of $a$ CIEOP reaction showing indistinct virion outlines suggesting antibody coating. 
failed to give lines with this antiserum.

Antigens derived from different fractions in a buoyant density gradient preparation gave lines 1 and 2 in the case of a fraction at a density of 1.36$1.38 \mathrm{~g} / \mathrm{ml}$ and lines 3 and 4 in the case of a fraction corresponding to a density of $1 \cdot 25-1.28 \mathrm{~g} / \mathrm{ml}$. The 1.36-1.38 $\mathrm{g} / \mathrm{ml}$ fraction contained whole virus particles by EM whereas we failed to find virus in the $1 \cdot 25-1 \cdot 28 \mathrm{~g} / \mathrm{ml}$ fraction.

A crude stool suspension from a calf positive for NCDV produced two lines with the reference antiserum HP.

\section{(b) Antisera}

Both convalescent guinea-pig sera designated HP and PP gave four precipitin lines with crude IGV positive stool suspension diluted 1:2. The preinoculation PP guinea-pig serum, but not the preinoculation HP guinea-pig serum, produced a single line with the crude stool IGV antigen. When highly purified antigen was reacted with this preinoculation PP antiserum no precipitin line was observed. Human sera collected three weeks following IGV infection when reacted with highly purified antigen mostly gave two lines of precipitin, occasionally one line only. Human serum collected in the acute phase of IGV disease and reacted with highly purified antigen usually gave no lines. An occasional acute phase serum, however, caused a weak line. If a crude IGV positive stool suspension was used as antigen, human convalescent phase serum gave one to four lines and acute phase serum gave either no line or an occasional single weak line of precipitation.

\section{(c) Optimal time of electrophoresis}

Using partially purified virus antigen and guinea-pig antiserum HP, CIEOP was conducted for varying times. Table I summarizes these findings and indicates that under the conditions of our test-system, 90 to 120 minutes proved the most satisfactory. Lines did not migrate further towards the anodal well after 60 minutes and did not appear more distinct after 90 minutes.

(d) Precipitin line staining

Unstained, reacted agarose slides when viewed over

\begin{tabular}{lllllll}
\hline \multicolumn{7}{c}{ Time (minutes) } \\
\cline { 2 - 7 } & 30 & 60 & 90 & 120 & 150 & 180 \\
\hline $\begin{array}{l}\text { Number of } \\
\text { lines }\end{array}$ & 0 & 4 & 4 & 4 & 4 & 4 \\
Intensity of & 0 & trace & strong & strong & strong & strong \\
\hline
\end{tabular}

Table I Varying times of CIEOP-runs and the number plus the strength of precipitin line obtained a dark-ground viewer generally failed to show 음 precipitin lines. Two staining methods were therefore evaluated as a means of intensifying antigen- $\stackrel{\mathscr{S}}{+}$ antibody reactions within the agarose. Amido black staining not only required an overnight washing step but proved less sensitive than the tannic acid method. In a comparative trial of these two staining proce- $\stackrel{\mathbb{\Omega}}{\Omega}$ dures using reference antiserum HP, and dilutions of partially purified IGV antigen, precipitin lines could be detected when antigen was diluted 1:100 (amido black) and 1:200 (tannic acid).

We then conducted further trials using tannic acid staining in an attempt to define both an optimal concentration of the reagent and a staining time. In our test-system $1 \%$ (w/v) tannic acid for 1.5 hours $\dot{\omega}$ proved optimal. Precipitin lines first appeared after $\vec{\theta}$ 10 minutes and at 1.5 hours maximal staining of lines in contrast to background staining wasachieved. 옥 Higher concentrations of tannic acid gave excess background staining.

\section{(e) Antigen stability}

Partially purified antigen kept at $4^{\circ} \mathrm{C}$ for one month $\vec{\varphi}$ showed virtually no loss of activity in CIEOP $\%$ reactions. Boiling or autoclaving this same antigen for 15 minutes caused a complete loss of activity. While heating at $50^{\circ} \mathrm{C}$ for 30 minutes caused no change, a further 30 minutes of incubation at this same temperature produced appreciably less well defined precipitin lines. Keeping this same antigen at $37^{\circ} \mathrm{C}$ for one week caused minimal loss of activity. If antigen was incubated with antiserum for 1 hour and then placed in the cathodal well and reacted, no precipitin lines were observed. Minimal loss of activity was also observed when an antigen positive stool was smeared and dried on a glass slide and kept at $4^{\circ} \mathrm{C}$ or at room temperature for 24 hours.

\section{COMPARISON OF THE CIEOP ASSAY TO EM AND CF}

(a) CIEOP versus EM for antigen/virus detection

For this comparison we used a crude IGV positive stool suspension, the highly purified virus, and the $\sigma$ partially purified virus. Electron microscopy was $N$ conducted directly, ie, without further concentration of the sample. Five EM grid fields were examined per dilution. Table II shows the end-point dilutions of the three virus suspensions beyond which no $\stackrel{\bar{D}}{\bar{D}}$ antigen or virions could be detected. Electron $\stackrel{5}{+}$ microscopy proved approximately four to eight 0 times more sensitive than CIEOP.

(b) CIEOP versus CF for antibody/antigen detection Doubling dilutions of the highly purified antigen versus doubling dilutions of guinea-pig antiserum 


\begin{tabular}{llll}
\hline \multirow{2}{*}{ End-point Dilutions } & \multicolumn{3}{l}{ Nature of IGV Suspension } \\
\cline { 2 - 4 } & Crude Stool & Highly purified $\begin{array}{c}\text { Partially } \\
\text { purified }\end{array}$ \\
\hline EM & $1 / 64$ & $1 / 128$ & $1 / 512$ \\
CIEOP & $1 / 8$ & $1 / 32$ & $1 / 64$ \\
\hline
\end{tabular}

Table II Comparison of CIEOP and EM as a means of detecting IGV antigen/virions in three different virus suspensions

HP were set up in box titration fashion to determine the relative sensitivity of the two systems. The optimal dilution of antigen (ie, the highest dilution of antigen giving a strong observable reaction with the highest dilution of antiserum) by CIEOP was 1 in 32 , and by CF was 1 in 256. The titre of antiserum was 1 in 256 by CIEOP and 1 in 2048 by CF.

In subsequent CIEOP field trials, the reference antiserum was diluted 1 in 10 for the detection of IGV antigen in stools. When human serum was later screened by CIEOP for the presence of IGV antibody, highly purified virus was diluted 1 in 5 as the challenge antigen.

\section{APPLICATIONS OF THE CIEOP ASSAY}

\section{(a) Detection of IGV antigen in stools}

Thirty-eight stools positive for IGV by our EM screening test were tested as crude stool suspensions for the presence of antigen by CIEOP using acute and convalescent HP guinea-pig serum. Thirty-five of these stools were positive for IGV antigen and three were negative. Thus, compared with our EM screening test, CIEOP was $92 \%$ effective.

One hundred stools negative by EM for IGV virions were also negative for this virus by CIEOP.

\section{(b) Detection of IGV antibody in human sera} CIEOP, using highly purified IGV as antigen, proved satisfactory for the determination of serological responses to IGV infection if serum was collected early in the acute phase of illness and then three weeks later. In a group of 14 patients found to have IGV infection by EM, nine showed antibody elevations from zero to $1: 4$ or greater, and five showed rises from $1: 2$ or $1: 4$ to $1: 8$ or $1: 16$ and greater. An adult in this latter category developed an antibody rise from 1:4 to $>1: 64$. Another five IGV positive patients in whom the initial blood sample was taken late in the course of illness failed to show a four-fold or greater change in antibody titre. Their initial serum samples contained antibody titres ranging from $1: 4$ to $1: 8$. A further six EM proven IGV patients from whom convalescent blood samples only were available for study showed antibody titres of $1: 8$ to $1: 32$.

Thirty serum samples from non-gastroenteritis patients per age group were tested for antibody to IGV by CIEOP and CF using highly purified IGV as antigen. Sera were screened at a dilution of $1: 2$ in the CIEOP test and at 1:4 in the CF test. In the CIEOP test either no line of precipitation was obtained or a single faint line and in some instances a single dense line of precipitation was observed. When CIEOP and CF findings of individual serum samples were compared it was found that both a dense line and a faint line of precipitation obtained by CIEOP corresponded to a CF titre of $1: 4$ or greater. In all instances, the finding of IGV antibody by CIEOP was confirmed by CF. Table III shows that $\mathrm{CF}$ is a considerably more sensitive and reliable test for the detection of IGV antibody in epidemiological studies.

\section{(c) Time study}

Using one operator, one power pack, and one electrophoresis tray, 20-30 test results on crude stools for the detection of IGV antigen could be generated within 4.5 hours. The 4.5 hour period was accounted for as follows:

\begin{tabular}{|c|c|c|c|c|}
\hline \multirow[t]{2}{*}{ Age Group } & \multicolumn{3}{|l|}{ CIEOP } & \multirow{2}{*}{$\begin{array}{l}\text { CF } \\
\begin{array}{l}\text { Percentage with IGV } \\
\text { Antibody }\end{array}\end{array}$} \\
\hline & Faint Precipitation Line & Dense Precipitation Line & $\begin{array}{l}\text { Percentage with IGV } \\
\text { Antibody }\end{array}$ & \\
\hline $\begin{array}{l}0-1 \text { week } \\
1 \text { week-3 months } \\
3 \text { months- } 6 \text { months } \\
6 \text { months-12 months } \\
1-2 \text { years } \\
2-3 \text { years } \\
3-5 \text { years } \\
5-10 \text { years } \\
10-20 \text { years } \\
20-30 \text { years } \\
30-40 \text { years }\end{array}$ & $\begin{array}{r}6 \\
7 \\
5 \\
7 \\
2 \\
11 \\
10 \\
0 \\
0 \\
0 \\
0\end{array}$ & $\begin{array}{l}0 \\
1 \\
0 \\
1 \\
6 \\
0 \\
1 \\
1 \\
0 \\
0 \\
1\end{array}$ & $\begin{array}{r}20 \\
27 \\
17 \\
27 \\
27 \\
37 \\
37 \\
3 \\
0 \\
0 \\
3\end{array}$ & $\begin{array}{l}73 \\
33 \\
31 \\
42 \\
44 \\
57 \\
68 \\
57 \\
58 \\
83 \\
73\end{array}$ \\
\hline
\end{tabular}

Table III Comparison of CIEOP and CF as a means of detecting IGV antibody in human serum in different age groups 
Setting up, that is, making agarose slides, cutting wells, and adding controls and reference sera plus crude stool suspensions to the wells took 1.5 hours; electrophoresis per se 1.5 hours; tannic acid staining a further 1.5 hours.

\section{Discussion}

The technique of CIEOP has been widely used for the detection of hepatitis B antigen. Recently, two papers have described the further use of CIEOP methods in diagnostic virology. Bohac and Derbyshire (1975) demonstrated transmissible gastroenteritis virus antigens in infected piglet intestinal contents and tissues; MacWilliam and Cook (1975) were able to type Echo and Coxsackie B viruses providing the antigen was first concentrated. In the work we present here, IGV antigen was detected by CIEOP in crude stool suspensions of patients with acute gastroenteritis. In order to obtain unequivocal and optimal results when testing for antigen in crude stool suspensions, we would stress the need for a highly specific reference antiserum and a suitable staining procedure for the demonstration of precipitin lines. The antiserum we found to be most serviceable was made in guinea-pigs inoculated with highly purified virus (Petric et al, 1975). No false positive results were obtained when 100 stools negative for IGV by EM were tested. The precipitin lines observed in our CIEOP system were regarded as specific on a basis of tests using antisera and antigens of varying degrees of purity, control antigens, and the finding by EM of antibody-virus complexes in precipitation line 2. These aggregations of virus particles presumably coated with antibody are similar to the immunoelectron microscopy photomicrographs published by Flewett et al (1974), Holmes et al (1974), and Kapikian et al (1974).

The relative sensitivity of CIEOP for the detection of antigen and antibody has been well studied in serum hepatitis (WHO Tech. Rep. Series, 1973, No. 512). While CIEOP was undoubtedly rapid, both relatively simple to perform and inexpensive, its sensitivity was of a lower order compared with radioimmunoassay, passive haemagglutination, and immunoelectron microscopy. In the case of IGV antigen/virion detection, we found that CIEOP was less sensitive than EM When unconcentrated stools from patients were examined by both methods, CIEOP detected 35 out of the $39(92 \%)$ that were positive for IGV by EM. The comparison was less favourable to CIEOP when an IGV positive stool and purified virus suspensions were serially diluted. Electron microscopy in this trial was graded about eight times more sensitive than CIEOP. We have so far not determined what the relative sensitivity of these two systems might be if virions in stools were concentrated by differential centrifugation before $\mathrm{EM}$, and if concentrated 'soluble' antigen together with the ultracentrifugal pellet were used as antigen $\overline{0}$ in CIEOP. In a preliminary study not yet reported, our unmodified CIEOP system detected adenovirus $\overline{\bar{\omega}}$ antigen in seven out of seven stool samples found to contain adenovirus by EM using a strong human adenovirus antiserum.

Although we have found that CIEOP is less $\vec{\circ}$ sensitive than EM, this slight disadvantage might $\overrightarrow{\vec{H}}$ well be tolerated in a diagnostic setting, because of $\omega$ the several obvious advantages that CIEOP offers. In particular, the unit cost per test is considerably less and the capacity of the laboratory to produce many more same-day test results is greatly increased. Our investigations also indicate that the IGV antigens $\vec{\theta}$ are relatively stable either when stored for 30 days 0 at $4^{\circ} \mathrm{C}$ or when heated at $50^{\circ} \mathrm{C}$ for 30 minutes. Thus, shipment of stool specimens to diagnostic centres should not unduly compromise test results.

Using guinea-pig antiserum produced by the inoculation of highly purified IGV, we were able to $\vec{\varphi}$ detect lines of precipitation in our CIEOP system $/ \overrightarrow{ }$ with a crude stool suspension of NCDV as antigen. Others (Flewett et al, 1974; Kapikian et al, 1975) have already shown that IGV and NCDV are related antigenically, by obtaining cross-reactions in immunoelectron microscopy, immunofluorescence, and complement-fixation test systems.

Our finding that CIEOP was a relatively poor test for the detection of IGV antibody in a serological survey in age groups ranging from the newborn up to 40 years was not unexpected in view of the known insensitivity of the CIEOP technique for demonstrating hepatitis B antibody. After 5 years of age very few of the population that we surveyed possessed detectable IGV antibody by CIEOP. In contrast, complement-fixation test results show a decline in the incidence of antibody after the immediate post-natal period, but by 6 months of age the incidence rises and reaches a level of $83 \%$ in the age group of 20 to 30 years. In addition to being relatively insensitive for antibody detection, $\sigma$ our CIEOP test results were difficult to read when $N$ faint lines as opposed to dense lines of precipitation $N$ occurred. A faint line was often difficult to observe against the background staining, and therefore readings tended to be subjective rather than objective. We are at a loss to explain the $20 \%$ incidence of antibody in the first week of life even though no antibody was found by CIEOP in the 20-30 year age group.

We thank the Medical Publications Department of The Hospital for Sick Children for secretarial help 
with the manuscript.

This study was supported by a grant from the Medical Research Council of Canada.

\section{References}

Bohac, J. and Derbyshire, J. B. (1975). The demonstration of transmissible gastroenteritis viral antigens by immunoelectrophoresis and counter-immunoelectrophoresis. Canad. J. Microbiol., 21, 750-753.

Bradstreet, C. M. P. and Taylor, C. E. D. (1962). Technique of complement-fixation test applicable to the diagnosis of virus diseases. Mth. Bull. Minist. Hlth Lab. Serv., 21, 96-104.

Culliford, B. J. (1964). Precipitin reactions in forensic problems. Nature (Lond.), 201, 1092-1094.

Davidson, G. P., Bishop, R. F., Townley, R. R. W., Holmes, I. H., and Ruck, B. J. (1975). Importance of a new virus in acute sporadic enteritis in children. Lancet, 1, 242-246.

Flewett, T. H., Bryden, A. S., Davies, H., Woode, G. N., Bridger, J. C., and Derrick, J. M. (1974). Relation between viruses from acute gastroenteritis of children and newborn calves. Lancet, 2, 61-63.

Holmes, I. H., Mathan, M., Bhat, P., Albert, M. J., Swaminathan, S. P., Maiya, P. P., Pereira, S. M, and Baker, S. J. (1974). Orbiviruses and gastroenteritis. Lancet, 2 , 658-659.

Hopkins, R., and Das, P. C. (1972). Improved sensitivity of the electrophoresis method by tannic acid for detection of Australia antigen. J. clin. Path., 25, 832-833.
Kapikian, A. Z., Kim, H. W., Wyatt, R. G., Rodriguez, W. J., Ross, S., Cline, W. L., Parrott, R. H., and Chanock, R. M. (1974). Reoviruslike agent in stools : association with infantile diarrhea and development of serologic tests. Science, 185, 1049-1053.

Kapikian, A. Z., Cline, W. L., Mebus, C. A., Wyatt, R G., Kalica, A. R., James, H. D., Jr., VanKirk, D., Chanock, R. M., and Kim, H. W. (1975). New complement-fixation test for the human reovirus-like agent of infantile gastroenteritis: Nebraska calf diarrhoea virus used as antigen. Lancet, 1, 1056-1061.

MacWilliam, K. M. and Cook, K. M. (1975). Counterelectrophoresis as a possible method for typing ECHO and Coxsackie B viruses. J. Hyg. (Lond.), 74, 239-244.

Martin, M. L., Palmer, E. L., and Middleton, P. J. (1975). Ultrastructure of infantile gastroenteritis virus. Virology, 68, 146-153.

Middleton, P. J., Szymanski, M. T., Abbott, G. D., Bortolussi, R., and Hamilton, J. R. (1974). Orbivirus acute gastroenteritis of infancy. Lancet, 1, 1241-1244.

Petric, M., Szymanski, M. T., and Middleton, P. J. (1975). Purification and preliminary characterization of infantile gastroenteritis virus (orbivirus group). Intervirology, 5, 233-238.

Wallis, C. and Melnick, J. L. (1971). Enhanced detection of Australia antigen in serum hepatitis patients by discontinuous counter-immunoelectrophoresis. Appl. Microbiol., 21, 867-869. 